\title{
Commentary: "Meta-Analysis on The Association of Genetic Polymorphisms of The Angiotensin- Converting Enzyme and Coronary Artery Disease in the Chinese population"
}

\author{
(iD)Baohong Xue \\ (iD) Lianping $\mathrm{He}^{1}$
}

1. College of experience industry, Anhui polytechnic university, Wuhu, Anhui, China Correspondence: Baohong Xue, road No.8 Beijing-241000 - Wuhu - China. Email: baohongxue@yeah.net

We read with great interest the study by Zhang and colleagues ${ }^{1}$ in which they demonstrated that the DD genotype of the angiotensin-converting enzyme gene might be a weaker risk factor for coronary heart disease in the Chinese Han population. We appreciate the contribution that this meta-analysis makes to the field. However, some questions should be addressed.

First, there are many risk factors for coronary artery disease, such as serum triglycerides ${ }^{2}$. Thus, the author should exclude some articles which included patients with some of these complications. Additionally, age also has an influence on the relationship between the DD genotype of the angiotensin-converting enzyme gene and coronary heart disease.

However, the authors failed to include more information in table one.

The authors further stated that "the database was statistically processed by Stata 12.0 " in the statistic treatment section. However, no figure produced by

\section{REFERENCES}

1. Zhang, Y. Huang, Y. Yang, T. and Zhou, W. Meta-Analysis on the association of Genetic polymorphism of the Angiotensin-converting enzyme and Coronary artery disease in Chinese population. Rev Assoc Med Bras 2019;65(6):923-929

2. Iin, Y. He, L. Wang, Q. Chen, Y. Ren, X. Tang, H., et al. Serum calcium levels are not associated with coronary heart disease. Vasc Health Risk Manag 2013;9: 517-20.

3. Alexander, P. E. Bonner, A. J. Agarwal, A. Li, S. A. Hariharan, A. T. Izhar, Z., et al. Sensitivity subgroup analysis based on single-center vs. multi-center trial status when interpreting meta-analyses pooled estimates: the logical way forward. J Clin Epidemiol 2016;74: 80-92. 